\title{
LOS RECORRIDOS DE FAMILIARIZACIÓN EN DESTINOS TURÍSTICOS Y SU RELEVANCIA COMO COMPONENTE DE LA LABOR DE RELACIONES PÚBLICAS DE MARKETING. El Caso Cuba
}

\author{
Dagoberto García Iglesias \\ Universidad de La Habana \\ Facultad de Turismo \\ dgarciaiglesias@gmail.com
}

\section{RESUMEN}

Los recorridos de familiarización de carácter promocional desempeñan un importante papel en tanto componente insoslayable de las Relaciones Públicas de Marketing que se despliegan en contextos turísticos. En el trabajo se analizan ciertas dimensiones de esta importante táctica comunicacional, resaltando los viajes destinados a familiarizar a periodistas con productos turísticos; de modo paralelo se realizan consideraciones sobre el estado de la cuestión en el caso cubano. Al respecto son valorados determinados elementos que han caracterizado este tipo de recorridos impulsados por el ministerio de Turismo desde 2006 y hasta 2010. El estudio (de naturaleza mixta, transeccional y empírico-descriptiva) concluye advirtiendo diez cuestiones a tomar en consideración por organismos y organizaciones del rubro para el diseño, implementación y evaluación de recorridos de familiarización en escenarios turísticos. Las técnicas empleadas son la investigación bibliográfica, revisión documental y entrevista semiestandarizada a directivos y funcionarios del sistema de turismo de Cuba.

Palabras clave: Cuba, destino turístico, propuesta, recorridos de familiarización, Relaciones Públicas de Marketing. 


\title{
FAM TRIPS IN TOURIST DESTINATIONS \\ AND THEIR IMPORTANCE AS A COMPONENT OF \\ THE MARKETING PUBLIC RELATIONS ACTIVITIES. \\ The Cuban Case
}

\begin{abstract}
Promotional - fam trips play an important role as key components of the Marketing Public Relations carried out in tourist contexts. This paper examines some dimensions of this important tactical communication, highlighting trips to familiarize journalists with tourist products; in parallel, considerations on the state of the Cuban case are made. With regards to those, certain elements are valued which have characterized this type of tours carried out by the Ministry of Tourism from 2006 to 2010. The study (of mixed nature, transectional and empirical-descriptive) concludes identifying ten issues to consider by the design, implementation and evaluation of fam trips in tourism scenarios agencies and organizations. The techniques used include literature and document review and semi standardized interview to managers and officers of the tourism system in Cuba.
\end{abstract}

Key words: Cuba, fam trips, Marketing Public Relations, proposal, tourist destination. 
"En la circunferencia, el comienzo y el fin coinciden"

Heráclito

\section{PREFACIO}

LAS RELACIONES PÚBLICAS (RRPP) son una novel área del pensamiento humano, matizadas por la afluencia en su corpus de conocimiento de diferentes actividades científicas, provenientes tanto del vasto entramado de las ciencias sociales y humanísticas, como de las áreas de las ciencias de la administración o gerencia y de las denominadas ciencias de la comunicación.

Estas «[...] constituyen, en las organizaciones donde son asumidas como el ente rector de los procesos comunicacionales, la disciplina de gestión de los vínculos entre aquellas y sus audiencias a la vez que una función directiva, cuya conceptualización e implementación debe producirse en virtud de la interrelación orgánica de etapas que comprenden la investigación de temas de interés para la institución y sus públicos, redacción y puesta en marcha de estrategias, programas y planes y evaluación del trabajo desplegado; todo ello a la luz de un arraigado sentir ético que propenda teleológicamente a la requerida integración de los intereses privados y públicos en cuestión, la total satisfacción de las partes interactuantes, así como al desarrollo global y la homeostasis social» (García Iglesias, 2010, Pág. 249).

Cuando las mismas se enfocan de modo preponderante al despliegue o sostenimiento de vínculos con públicos enclavados en ámbitos comerciales, se apela al esquema de las Relaciones Públicas de Marketing (RPM) -uno de los más socorridos internacionalmente-, también conocidas como RRPP promocionales o Brand Public Relations, con independencia de esta predilección, constatada igualmente en el contexto cubano (García Iglesias, 2009), es válido acotar que las RPM pueden resultar insuficientes para la feliz realización de determinadas tareas que también son de competencia para la disciplina en cualquier grupo social. «Cuando las relaciones públicas se conciben sólo como atención a los requerimientos, necesidades y quejas de los clientes y el profesional de relaciones públicas se convierte en un simple tramitador de las mismas, se deja fuera todo el arsenal de actividades y funciones del área, algunas de extrema importancia para la entidad, como el asesoramiento a la dirección, la comunicación con todas las áreas y públicos, las relaciones con la comunidad, entre otras. Además de que en esta posición, los profesionales se encuentran alejados en el organigrama de la Dirección General, lo 
que les imposibilita cumplir con su rol de "boca y orejas de las entidades, organismos y organizaciones para los que trabajan”» (Rivero Hernández, 2009, Pág. 36).

En el caso de destinos, organismos, organizaciones y productos turísticos, los postulados de las RPM han merecido la atención de una extensa lista de estudiosos, investigadores y profesionales, en especial por lo arraigada que se encuentra en estos escenarios la noción de lucro y ventas. Para los mismos, la comunicación con fines comerciales es la más relevante de todas las funciones que ha de desplegar RRPP, actividad concebida de modo frecuente como « [...] un instrumento promocional con una importancia relativa mucho mayor en turismo que en otros sectores» (Serra, 2003, Pág. 294).

De este modo, las RRPP son valoradas como una de las más relevantes promoherramientas entre todas las que se emplean en contextos turísticos, sin desestimar la notoriedad de otras como la Publicidad, Promoción de Ventas, Venta Personal, Merchandising, etcétera. Ello viene dado por la carencia en estas últimas de una visión más dialógica y horizontal de los procesos de comunicación y vinculación, tomando como patrón de referencia a las RRPP, las cuales tienen el mayor protagonismo a la hora de ofrecer un tratamiento ajustado a las necesidades y expectativas de los públicos -fundamentalmente visitantes, excursionistas, turoperadores (TTOO), agencias de viaje (AAVV), líneas aéreas (LLAA) y profesionales de la prensa-, lo cual ciertamente en el turismo apunta, más que a un valor añadido, a una necesidad perenne en los dinámicos procesos de oferta-demanda-consumo.

Pero cualquiera sea el enfoque esgrimido para la implementación de los presupuestos de las RRPP (posición comercial o integradora), en un destino turístico los profesionales del área realizan esfuerzos disímiles para hacer saber a públicos de interés (actuales y potenciales), todo lo que pueden ofrecerles las organizaciones o productos que representan, en pos de captar su atención, satisfacer las necesidades existentes y, de modo preferente, lograr la elección hacia los últimos frente a los de la competencia. Para lo anterior, entre otras importantes tácticas, se valen de recorridos o viajes de familiarización (también conocidos como fam trips): significativo modo de lograr un acercamiento entre un destino y sus públicos de relevancia, fundamentalmente operadores y medios de comunicación. Aunque no serán abordados en este trabajo, los fam trips también pueden integrarse por trabajadores del rubro turístico, autoridades con 
incidencia directa o indirecta sobre el sector, grupos de presión o de interés, entre otras audiencias. En estos casos los fines varían, si bien su contribución a metas comerciales, aunque de modo indirecto, se mantiene vigente.

En el presente trabajo se realiza un análisis de dimensiones esenciales que sustentan una aproximación al estudio de los viajes de familiarización en tanto una de las más notorias tácticas de las RPM en destinos turísticos, desarrollando de modo paralelo una valoración empírica del comportamiento del particular en el espacio cubano, fundamentalmente a partir de los esfuerzos desplegados en este sentido por el Ministerio de Turismo (MINTUR) en el quinquenio 2006-2010, período en que se reportaron cifras récords dentro de la historiografía cubana del turismo, donde en 2006 arribaron al país por tercer año consecutivo más de dos millones de visitantes, tendencia que se ha mantenido de modo ininterrumpido desde entonces, lo cual permitió que en 2010 se registrase la mayor afluencia de visitantes al país jamás experimentada: más de dos millones 531 mil. Todo ello como resultado, entre otros factores, del aumento y mejora constante de la planta hotelera (actualmente entre los hoteles de cuatro y cinco estrellas aglutinan más del $70 \%$ del total existente en el país) y de la red extrahotelera, del perfeccionamiento de los servicios aduanales y aeroportuarios y del incremento paulatino de los presupuestos asignados a la actividad de comunicación promocional. De modo conclusivo son expuestas diez coordenadas a tomar en cuenta por dispositivos de RRPP y comunicación en organismos y organizaciones del sector para una superior concepción, organización y evaluación de los efectos alcanzados a partir del despliegue de recorridos de familiarización.

Este estudio puede resultar de interés para organismos y organizaciones de corte turístico, especialmente en lo relativo a comunicación y RRPP, atendiendo a que arroja enfoques concernientes a una de las más importantes herramientas del campo que en la actualidad se aplica de modo incesante en destinos internacionales. Actividades tan permeadas por la subjetividad y el empirismo como lo son aquellas, siempre tendrán a bien el impulso de esfuerzos como el presente, en especial, cuando favorezcan una más acertada toma de decisiones respecto a recursos a disponer en pos de la creación, mantenimiento y fortalecimiento de vínculos con públicos de importancia capital para el renglón. 


\section{PRECISIONES METODOLÓGICAS}

La investigación constituye un estudio de caso único de tipo global, asentado en la perspectiva mixta por cuanto se integran armónicamente posiciones del paradigma cuantitativo y del cualitativo, pero con preponderancia del segundo; posee una naturaleza transeccional y empírico-descriptiva. Asimismo, se trata de una pesquisa exploratoria atendiendo a la inexistencia constatada, en centros de estudios e investigación nacionales u otro tipo de instituciones relacionadas con el desarrollo del turismo, de referentes que puedan sistematizarse en condición de antecedentes.

Las unidades de análisis del trabajo fueron la producción científica localizada, proveniente tanto del contexto cubano como internacional, la cual se tomó como material para el enriquecimiento de los juicios del autor en un sentido teórico-conceptual; mientras que para una ponderación del tema seleccionado en el plano real-operacional se tuvo en cuenta, fundamentalmente, documentación institucional centrada en su objeto, atesorada en grado sumo por la dirección de Comunicación del MINTUR (área rectora del desarrollo de las RRPP en el sistema de turismo) así como por la estructura homóloga y otras instancias de gestión del grupo internacional de turoperadores y agencias de viajes Havanatur, S.A. ${ }^{1}$.

Atendiendo a lo anterior, las técnicas de investigación apeladas son la revisión bibliográfica y el análisis documental (tanto de soportes impresos como digitales). También se desarrollaron entrevistas semiestandarizadas (6) a miembros de la dirección de Comunicación del MINTUR y de otras áreas e instancias de gestión de dicho organismo, así como a especialistas de la materia en la referida entidad, para complementar o cuestionar los enfoques y resultados arrojados por el resto de las herramientas empleadas.

\section{FUNDAMENTACIÓN TEÓRICO-CONCEPTUAL}

Lo que en este trabajo se maneja como recorridos de familiarización ha sido también asimilado por la teoría de las RRPP como visitas dirigidas de públicos específicos a una institución cualquiera (relativos, casi siempre, al ámbito externo de la misma) y homogéneos entre sí, como regla general.

1 Havanatur Es es el único Tour Operador de capital totalmente cubano, con más de 30 años de experiencia, cuenta con 13 agencias en varios destinos del mundo (3 en México, 1 en Canadá, Bahamas, Argentina, Chile, Reino Unido, España, Italia, Francia, Alemania y Rusia respectivamente). En Cuba cuenta con otras dos agencias prestatarias de servicios marcadamente receptivos. 
En el caso de organismos y organizaciones del rubro turístico, estos periplos tienen como cometido exponer a sujetos de su interés potencialidades del sector; estado de desarrollo y comercialización de destinos; lugar ocupado respecto a la competencia; entre otras cuestiones, en aras de que posteriormente los participantes se conviertan en portavoces a amplia escala de lo apreciado e incidan en la opinión pública de manera favorable, con la consiguiente elevación de las probabilidades de que los receptores de estos mensajes refuercen sus presunciones en torno a lo sostenido con anterioridad, o las transformen de manera parcial o total (para bien de la entidad o producto, preferentemente).

Los recorridos de familiarización se inscriben en la misma línea de actuación del resto de las acciones de RRPP desarrolladas en cualquier organización: determinar las estrategias y tácticas de comunicación y acción necesarias para incidir, moldear y transformar estados de opinión acorde a los intereses de las partes interactuantes. La lógica de funcionamiento de un fam trip (diagrama $\mathrm{N}^{\circ} 1$ ) es la siguiente:

- Los organismos y organizaciones turísticas, previa definición de intereses, atributos y productos que se desea comercializar y posicionar en el mercado, diseñan recorridos por instalaciones (hoteleras, de restauración, marinas, de recreación...), regiones turísticas, red de establecimientos pertenecientes a una única organización o bien combinaciones de las anteriores alternativas.

- Los individuos o grupos interesados y posteriormente aceptados por los organizadores, se aproximan a cualquiera de estas opciones gracias al recorrido desplegado, aprehenden sus particularidades, las interiorizan y luego -atendiendo a su estatus de personalidades y/o de líderes de opinión-, se hacen eco de lo experimentado hacia terceros que no han tenido la oportunidad de involucrarse de manera estrecha al respecto. En el caso de decisores de organizaciones intermediarias entre el destino y sus clientes finales (TTOO, AAVV, LLAA...), el fam trip puede constituir un factor preponderante para la concreción de una decisión de índole comercial. 


\section{Diagrama $\mathbf{N}^{\mathrm{o}} 1$}

Lógica de funcionamiento de los recorridos de familiarización en destinos turísticos, como parte del esfuerzo de comunicación en función de la gestión de ventas

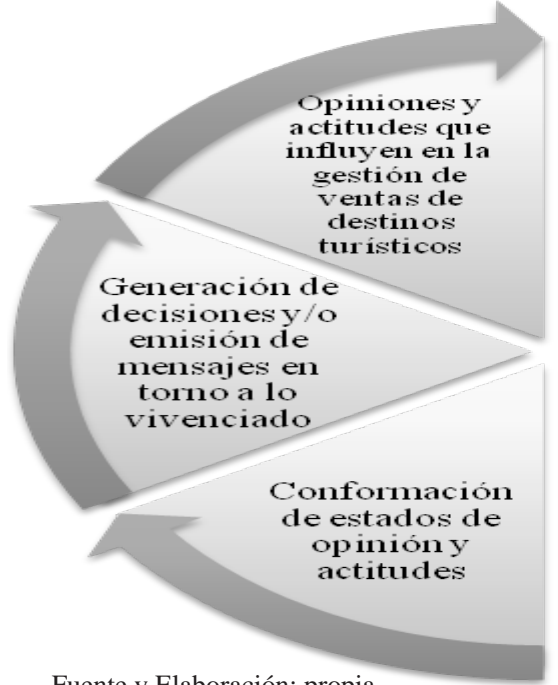

Fuente y Elaboración: propia

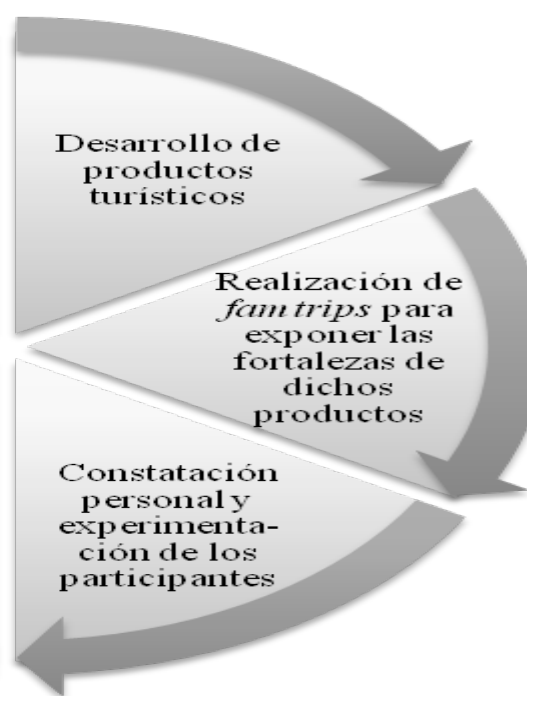

Los motivos que suscitan la organización de fam trips son heterogéneos así como también lo son su alcance temporal, geográfico y temático. Alg unos de los más importantes que pudiesen referirse son:

- Como parte de las rutinas productivas, entendidas estas como procedimientos de trabajos estandarizados y naturalizados por el quehacer diario» (George Farray y González Lucena, 2009, Pág. 87), de las estructuras de comunicación y RRPP de organismos y organizaciones turísticas.

- Como preámbulo, durante y/o después de concluido algún evento de corte turístico o afín al rubro.

- A partir del (re)lanzamiento al mercado de productos, regiones u organizaciones turísticas.

- Dado el (re)establecimiento de un vuelo de una Línea Aérea a un destino determinado.

- En tanto elemento consustancial de producciones fotográficas o audiovisuales 
que se generan en un destino, promovidas generalmente por este, las cuales casi siempre desembocan en campañas publicitarias.

- Combinación de algunas de las anteriores y de otras alternativas.

Un recorrido de familiarización es un evento estructurado en diferentes momentos y como tal debe concebírseles, especialmente en función de las tres etapas en las cuales se constituyen (antes, durante y después). Estas acciones resultan espacios de integración de diversas tácticas de acción y comunicación como producción y distribución de soportes impresos, digitales y audiovisuales; elementos del protocolo y el ceremonial; prestaciones o solicitud de patrocinios; lobby o cabildeo; trabajo con los medios de comunicación de masas; entre otras, por lo cual sus costos en términos estrictamente financieros pueden ser muy elevados, aunque si se les valora comparativamente con las sumas requeridas para cada una de estas acciones de forma aislada, puede concluirse que los gastos son en realidad bien inferiores.

Antes de realizarse un recorrido de familiarización -cualquiera sea su leit motivhabrán de ser contestadas, al menos, dos interrogantes vertebrales: ¿qué se desea mostrar para su posterior difusión? y ¿quién o quienes resultan de interés como participantes dada su condición de públicos de alta visibilidad respecto a los intereses de los organizadores?

Obviar cualquiera de las dos en la fase de conceptualización del recorrido implica, en primer lugar, desplegar programas carentes de sentido o de una línea temática preestablecida. Por otra parte, no tener claridad meridiana respecto a sus potenciales integrantes provocaría la convivencia por días y hasta semanas de individuos con cosmogonías diversas (y hasta puede que antagónicas), provocando ello un estado de malestar generalizado que, de seguro, no reportará luego dividendos apetecibles para las organizadores. «En el pasado estos viajes solían ser masivos y estaban mal planteados, pero hoy en día son más cortos y selectivos» (Wilcox et al, 2001, Pág. 478).

La elección de los participantes es de suma importancia, como ya se expuso, pues se trata de personas que devienen en una suerte de parientes cercanos, casi siempre en escenarios ajenos geográfica y culturalmente a sus entornos de origen. Esto, sin embargo, debe apreciarse también como una potencialidad de los recorridos de familiarización atendiendo a que en los mismos « [...] se consigue un ambiente especial que facilita la vinculación del personal comercial que los patrocinadores han puesto a cargo del grupo 
con los miembros invitados. Lo que refuerza los lazos comerciales establecidos entre las empresas, al facilitar además del conocimiento del producto la fidelización hacia el sistema de ventas y de ayuda que se soportan, en su caso, en unas buenas relaciones entre el vendedor de la minorista y el de la mayorista, línea aérea o cadena hotelera» (Muñoz Oñate, 2000, Págs. 406-407).

Como en casi todos los recorridos de familiarización existe de trasfondo un interés comercial, un muy apelado modo para medir su eficacia estriba en la asociación directa entre su desarrollo y la toma de decisiones favorables por parte de los participantes (en este caso socios o posibles partners de la operación turística) en torno al destino u organización de referencia. Sin embargo, aunque con un fin promocional estos viajes constituyen una táctica de las RRPP, y como tal deberá realizarse la evaluación de su efectividad en términos comunicacionales y no sólo de Marketing, desarrollando en el ocaso de los mismos la ponderación de los resultados alcanzados respecto a los objetivos preliminares trazados: conocimiento, reconocimiento, notoriedad y mayor difusión de lo explorado durante el periplo.

Asimismo, no es ocioso precisar que los fam trips deben preconcebirse como parte de planes o campañas de RRPP y comunicación, previendo el modo en que contribuirán al alcance de los objetivos específicos de estas áreas y de organismos y organizaciones turísticas en general, así como la manera en que se complementarán con el resto de las tácticas previstas para un período de actuación determinado, entre otras cuestiones inherentes a la planeación en este campo (presupuesto disponible, calendarios para la realización de aquellas, entre otras).

Los grupos partícipes en recorridos de familiarización por contornos turísticos y con fines promocionales, pueden integrarse, entre otros, por:

- Personalidades, directivos y otros decisores de la actividad turística y/o de renglones socioeconómicos afines (aeronáutica civil, comercio exterior, transporte...).

- Público especializado, fundamentalmente Tour Operadores, Agencias de Viajes, Líneas Aéreas, Promotores de Ventas y otras audiencias que fungen como intermediarios entre un destino y sus clientes finales.

- Profesionales de la prensa, fotógrafos, redactores publicitarios y otros de 
naturaleza cercana que se desempeñan tanto en medios especializados en temas turísticos como en los dirigidos al gran público final.

- Una combinación de algunas o de todas las alternativas anteriores.

Cualquiera de estas opciones singulariza la acción e incrementa su complejidad a partir del criterio de especialización de los participantes. Sin embargo es en el caso de la prensa, atendiendo al rol social desempeñado por dicho gremio, donde los recorridos de familiarización pueden tornarse mucho más álgidos y precisar una organización superior. Lo anterior ratifica lo escrito por, el mexicano Miguel A. Acerenza (1985) quien identifica la existencia de tres tipos de recorridos de familiarización, en función de los públicos que los componen:

- Viajes de cortesía, o a tarifa reducida: organizados para agentes de viaje y/o empleados de aerolíneas, con el fin de hacerles saber las potencialidades de un determinado destino o producto turístico.

- Viajes de hospitalidad: aquellos que se prevén para la prensa y escritores de turismo, para el logro posterior de trabajos periodísticos que ensalcen todo lo que lograron experimentar durante su estancia.

- Visitas promocionales: concebidas hacia el mercado emisor, « [...] para presentar un destino, sus facilidades, y las ayudas de ventas disponibles para facilitar su venta en el mercado consumidor» (ibídem, Pág. 129).

La prensa: vedette de los recorridos de familiarización en destinos turísticos

Como parte de la labor de integración entre los destinos turísticos y sus organizaciones con medios de comunicación, una importante herramienta a considerar son los recorridos de familiarización por regiones o productos de interés para los primeros.

Numerosos son los autores que convienen en que « [...] un sector en el que continuamente hay que realizar viajes de prensa es el de la industria turística» (Rojas Orduña, 2005, Pág. 189). Estas visitas son sumamente delicadas, por la connotación posterior que entrañan para los promotores; al respecto Piedra Rodríguez alerta: «aunque las visitas en general constituyen una acción de Relaciones Públicas de las más útiles y socorridas, las visitas de la prensa requieren una especial atención. [...] nos encontramos ante una oportunidad de comunicación en sí misma, además de una vía para ofrecer 
información valiosa» (en colectivo de autores, 2002, Págs. 74-75).

«El objetivo de este tipo de viajes es dar a conocer la oferta turística de un destino determinado entre los informadores para que éstos la difundan a través de los medios de comunicación» (Rojas Orduña, 2005, Pág. 190). Por ende, dichos periplos adquieren una connotación especial, sobre todo porque las valoraciones (inmediatas y posteriores) del mencionado público no sólo tienen una incidencia (directa e indirecta) en su actitud hacia el organismo u organización que los generaron, sino que estas trascienden ese marco para contribuir al imaginario construido socialmente ${ }^{2}$ por sus receptores sobre el destino o producto centros de atención de los trabajos periodísticos.

Los recorridos de prensa (local, regional, nacional y/o extranjera) constituyen la contrapartida de las giras de profesionales de las RRPP y de otras prácticas cercanas por medios de comunicación (en inglés media tours); en este caso son los especialistas del Periodismo los que se desplazan hacia puntos declarados como de interés por las organizaciones del rubro. Los mismos pueden integrarse por un único periodista, reducidos grupos de ellos (pertenecientes a un mismo medio o país) o por sumas considerables, sobre todo cuando se trata de algún evento o acontecimiento singular precisado de una amplia repercusión mediática, al que luego se le añade como parte de su programa uno o varios fam trips.

De cualquier modo, un cúmulo de conjeturas deben ser tenidas en cuenta tanto para la organización de viajes de familiarización con este público como para otros a los que ya se ha hecho referencia. Sin embargo es la prensa un sector donde cristalizan con mayor intensidad algunas de las concebidas como frecuentemente constatables:

Habrá que empezar diciendo que no siempre los periodistas interesados en participar constituyen paladines dentro de su gremio profesional, por lo que los organizadores deben mostrarse atentos frente a posibles individuos cuyo último interés será diseminar de algún modo sus experiencias, o al menos no dentro del radio de interés de aquellos.

De igual forma, no son todos los exhortados los que aceptan integrarse a un recorrido de familiarización asumiendo la totalidad de las reglas establecidas por los 2 «Los imaginarios sociales, [...], dan cuenta del proceso de atribución de significados a elementos que nos son total 0 parcialmente ajenos, y mediante el cual los sujetos crean, recrean y se apropian de la realidad» (Cordero Durán y González Hernández, 2008, Pág. 88). 
organizadores. Mas aquellos que temen ser coaccionados posteriormente u otros cuyos medios de comunicación no consienten la totalidad de los requerimientos, también deben ser escuchados de antemano e incluso persuadidos por los promotores de abandonar posturas hostiles, apelándose en todo momento a la seriedad y compromiso de sus instituciones para con el trabajo que desarrollan y al desinterés prevaleciente en torno a la manipulación de la realidad a constatar (si es que realmente es ese el móvil impulsor de la acción).

Tampoco debe suponerse que el asumir todos los gastos de los participantes es condición irrebatible para que el efecto de la acción sea inmediato, automático y hasta cierto punto acrítico de lo vivenciado. Es muy común observar a organizadores no del todo satisfechos con los resultados obtenidos en el corto plazo pues, o no existe una repercusión a la altura de lo previsto o lo reflejado no es del todo concomitante con las estrategias de comunicación, comercialización y desarrollo existentes. Sépase que algunos periodistas abandonan el paradigma militante de su actuación profesional frente a suculentas ofertas mientras otros (sin desperdiciar la oportunidad en todos los órdenes que representan estas travesías), no cejan en el mantenimiento de los valores, ética e ideología profesionales de su quehacer diario.

Probablemente si los organizadores, como premisa, convienen en que la realidad no deberá ser teatralizada u ocultada a los periodistas, demostrando en todo momento total aceptación de lo publicado (siempre que el tratamiento periodístico sea lineal, respetuoso y ajustado al criterio de verdad, aunque no esté totalmente ajustado a los intereses administrativos prevalecientes), para próximas ediciones de los periplos u otras acciones afines, estos medios de comunicación pudieran ser más flexibles y acercarse un tanto más a las peticiones de los organizadores. Sólo las verdaderas relaciones de confianza con la prensa pueden garantizar vínculos imperecederos entre este público y organismos y organizaciones turísticas.

También es saludable dejar claro que, tanto en un recorrido de familiarización como en cualquier otra táctica comunicacional con la prensa, el respeto y el trato de pares de relacionadores públicos hacia los periodistas constituye la base para una vinculación ética y duradera entre la organización promotora y este gremio. Ambas partes conocen lo suficientemente bien su rol social así como los grados de interdependencia existentes, con lo cual resulta innecesaria cualquier otra acotación al respecto; mientras que actos 
sobredimensionados de hospitalidad, para una buena cantidad de los últimos, sólo serán considerados como atenciones que en su calidad de profesionales de la información masiva merecen.

Por último, téngase siempre en cuenta que sólo el balance entre el desarrollo de recorridos de familiarización y el empleo de otras tácticas de comunicación y acción con la prensa, garantiza una armoniosa vinculación organización turística-mass media (diagrama $\mathrm{N}^{\circ}$ 2). Considerar a los primeros como la única alternativa a emprender al respecto raya en lo incauto, a la vez que evidencia una comprensión sesgada de la amplia dimensión del fenómeno de la comunicación de masas y su importancia para el cumplimiento de los propósitos misionales ${ }^{3}$ de cualquier institución.

\section{Diagrama $\mathbf{N}^{\circ} 2$}

Espacio e interacción de los recorridos de familiarización con otras tácticas de vinculación entre organismos y organizaciones turísticas y medios masivos de comunicación

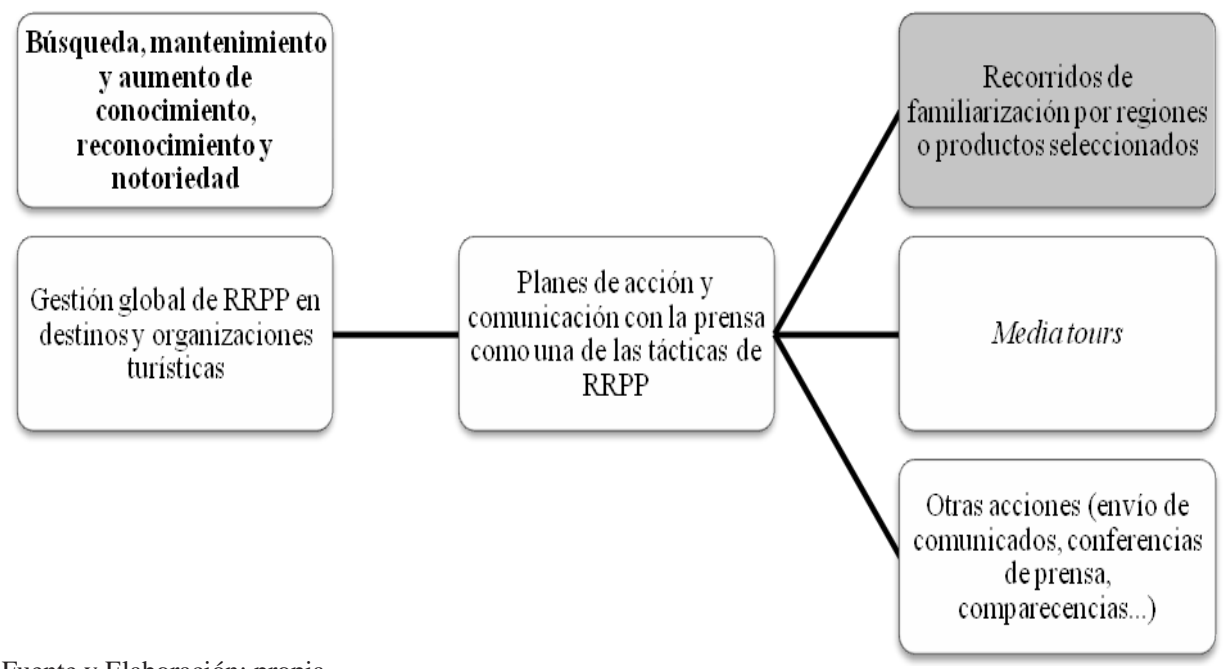

Fuente y Elaboración: propia

En lo concerniente a la evaluación del resultado de estos viajes, debe tenerse en cuenta que en el corto y mediano plazos el empleo de instrumentos como aplicación de cuestionarios y entrevistas a participantes para detectar su nivel de satisfacción, análisis de 3 « [...] propósitos misionales o declaraciones estratégicas, a saber: Misión, Visión, Valores, Objetivos de la empresa (todos los cuales deben estar actualizados y ser inspiradores) [...]» (Rivero Hernández, 2010, Pág. 107). 
contenido de los trabajos publicados así como de los índices de audiencias (ratings) que alcanzaron, entre otros, posibilitan una aproximación a los reales efectos conseguidos.

No es aconsejable valorar los mismos sólo en función de la optimización de presupuestos lograda gracias a la aparición de trabajos periodísticos en espacios mediáticos, en lugar de meros anuncios publicitarios ${ }^{4}$. Aunque estos son análisis que los directivos aprecian en grado sumo, los profesionales de las RRPP deben trabajar con este público para lograr mayores índices de sensibilidad sobre el hecho de que un publirreportaje u otro trabajo de matiz periodístico-promocional (crónica, reseña, comentario...), logrado como resultado de una visita de prensa al destino, no debe parangonarse con un mensaje estrictamente publicitario sobre todo en términos económicos: los efectos de ambos productos comunicacionales -aunque pudieran estar equifinalizados- no son necesariamente idénticos.

En esencia, «la solución final de la buena práctica para la evaluación mediática no es limitarse a contar el tiempo y el espacio mediático logrado y su equivalencia publicitaria, sino que consiste también en evaluarlo en términos cualitativos a través de un análisis del contenido» (Seaton y Woodward, 2004, Pág. 145).

\section{ANÁLISIS DE RESULTADOS}

Cada año, tanto el MINTUR como las entidades del sistema nacional de turismo (fundamentalmente las que poseen objetos sociales relacionados con la prestación de servicios de alojamiento, actividad extrahotelera, turoperación y agencias de viajes), destinan considerables sumas financieras y recursos materiales al diseño y aplicación de estrategias, planes y campañas de comunicación, privilegiando de modo sumo el ámbito comercial. Operacionalmente, esta labor cobra vida en función de tres importantes herramientas o prácticas:

- Publicidad: en especial a través de la implementación de la campaña de destino en los más importantes mercados emisores hacia Cuba;

- Promoción de ventas: apreciada en la realización de recorridos promocionales por

4 Son varios los autores que fustigan el empleo del método de equivalencia publicitaria o AVE por sus siglas en inglés (Advertising Value Equivalente), a través del cual se busca información en términos de ahorro para la organización atendiendo al costo de la inserción de un mensaje publicitario en idéntico espacio al ocupado en páginas de la prensa o tiempo que se encuentra al aire, determinado material periodístico de matiz más informativo-explicativo. 
los principales destinos emisores y en la conformación de ofertas para estimular los esquemas comerciales de productos turísticos; y

- RRPP: que aún con un enfoque limitado en exclusivo al plano promocional, tienen una preponderancia insoslayable dentro de la labor global de comunicación, complementando o facilitando de algún modo la aplicación de las anteriores y otras herramientas.

Como parte de esta labor de RRPP, anualmente se gestan gran número de recorridos de familiarización por el destino Cuba. En las políticas de comunicación diseñadas por el MINTUR, se establece que los mismos « [...] tienen como objetivo fundamental que los participantes logren conocer, vivenciar, experimentar los destinos turísticos y sus productos. Una parte de ellos se componen de profesionales vinculados directamente al turismo: agentes de viaje, turoperadores y, en ocasiones, participan también profesionales de la prensa. Otros están compuestos solamente por profesionales de la prensa, generalmente especializados en los temas turísticos» (2005).

Los recorridos de familiarización se ponderan como una de las más trascendentales y onerosas herramientas de comunicación comercial, compartiendo espacio con otras como organización de eventos de carácter promocional o especializado; participación en convenciones y ferias que internacionalmente conciben los más importantes mercados emisores al país; así como la conmemoración de celebraciones de carácter turístico y otras de relevancia para Cuba.

Durante el período 2006-2010 se desarrollaron como parte de estrategias y planes de comunicación y RRPP, un importante cúmulo de viajes de familiarización. Los motivos más recurrentes que suscitaron su realización fueron:

- Los que tuvieron lugar como parte de programas de eventos turísticos fomentados por el MINTUR y/o las entidades del sistema de turismo.

- Aquellos que se efectuaron como componente de las actividades previstas antes, durante y/o una vez concluidos determinados eventos que se celebraron en Cuba a partir de la captación internacional de su sede, o como resultado de acuerdos de comunicación/promoción conjunta ${ }^{5}$ suscritos entre el organismo y socios de

5 Apelada también como comunicación cooperada o acuerdos de co-marketing. « [...] Consiste en la realización de acciones de comunicación de naturaleza diversa, con socios de la operación turística, fundamentalmente TTOO y LLAA, donde estos últimos proporcionan un por ciento de la inversión y la otra parte la asume el Destino Cuba» (García Iglesias, 2009, Pág. 87). 
la operación turística.

- Los desplegados en virtud de lo planeado anualmente por el MINTUR y las entidades del sistema de turismo en materia de comunicación y RRPP para los principales mercados emisores al destino.

Entre todos estos recorridos, un importante papel lo han desempeñado los dos primeramente enunciados atendiendo al número y tipología de participantes, recursos destinados e impacto comunicacional alcanzado. El contexto en el cual se han gestado, indudablemente, es factor desencadenante de esta connotación.

Los eventos de orden turístico más relevantes que se organizaron en Cuba, fomentados directamente por el ministerio, durante el mencionado quinquenio y en los cuales se previó la realización de recorridos de familiarización, fueron: Feria Internacional de Turismo FITCuba (periodicidad: anual), Evento Internacional de Fotografía Subacuática FOTOSUB (anual) y Evento Internacional de Turismo de Naturaleza TURNAT (bianual). De los tres FITCuba es, sin dudas, el de mayor trascendencia en todos los órdenes.

Con más de treinta ediciones ininterrumpidas, es el evento de la industria turística cubana (con carácter profesional) de mayor proyección mundial a la vez que espacio de excelencia para la promoción del destino. En casi todas las ediciones de interés para este trabajo, fueron desarrollados dos recorridos de familiarización como parte de su programa: uno, integrado por TTOO, AAVV, LLAA, hoteleros, personalidades gubernamentales, representantes de organizaciones internacionales de turismo y otros públicos, todos en condición de invitados especiales del MINTUR; y otro, conformado por prensa asistente al evento. En total, tomaron parte en dichos recorridos 1000 profesionales (cuadro $\mathrm{N}^{\circ}$ 1):

\section{Cuadro $\mathrm{N}^{\circ} 1$}

Tipología de participantes en viajes de familiarización desarrollados como parte del programa de FITCuba (2006-2010)

\begin{tabular}{|c|c|c|c|c|c|c|}
\hline \multirow{2}{*}{ Público participante } & \multicolumn{5}{|c|}{ EDICIONES DE FITCUBA } & \multirow{2}{*}{ Total } \\
\cline { 2 - 7 } & $\mathbf{2 0 0 6}$ & $\mathbf{2 0 0 7}$ & $\mathbf{2 0 0 8}$ & $\mathbf{2 0 0 9}$ & $\mathbf{2 0 1 0}$ & $\mathbf{3 0 1}$ \\
\hline Público especializado & 53 & 105 & 0 & 75 & 68 & $\mathbf{6 9 9}$ \\
\hline Prensa & 57 & 120 & 170 & 187 & 165 & $\mathbf{1 0 0 0}$ \\
\hline TOTALES & $\mathbf{1 1 0}$ & $\mathbf{2 2 5}$ & $\mathbf{1 7 0}$ & $\mathbf{2 6 2}$ & $\mathbf{2 3 3}$ & $\mathbf{1 0 0}$ \\
\hline
\end{tabular}

Fuente: cifras oficiales del MINTUR

Elaboración: propia 
Como puede apreciarse, ha existido una mayor propensión a girar invitaciones para participar en estos recorridos a la prensa; ello representa más del doble del número de sujetos pertenecientes a audiencias relacionadas directamente con metas comerciales del destino. Asimismo, el número de periodistas asistentes a dichos periplos evidenció un crecimiento año tras año, el cual fue interrumpido en la última edición del evento analizada. El pico de participación en general en el quinquenio se produjo en 2009, año en el cual la prensa invitada al viaje de familiarización efectuado marcó cifra récord para este tipo de actividades dentro del programa de FITCuba.

De la prensa participante en cada edición del evento, ha tomado parte en sus recorridos de familiarización, de modo mayoritario, la invitada desde los mercados emisores al destino. Con cifras muy inferiores, también han asistido representantes de medios de comunicación acreditados ante el centro de Prensa Internacional del ministerio de Relaciones Exteriores (CPI-MINREX); en ambos casos, intervinieron medios de carácter especializado en la actividad turística y también dirigidos al gran público. En la edición de 2010 se retomó la iniciativa de incorporar a estos periplos a prensa nacional cuyo público meta incluye a la población cubana: Agencia Cubana de Noticias (ACN), Agencia Informativa Latinoamericana Prensa Latina (PL) y canal de televisión Cubavisión Internacional.

Los dos recorridos, efectuados casi siempre una vez concluido el evento, tuvieron lugar de modo independiente con el fin de ofrecer a cada público la respuesta precisa a sus demandas de experimentación y conocimiento, si bien las regiones a visitar fueron coincidentes en su gran mayoría, tomando en consideración aquella(s) a la(s) cual(es) se dedicó cada edición de este:

- 2006: región central de Cuba (provincias de Cienfuegos, Villa Clara y Sancti Spíritus).

- 2007: cayos de Cuba (cayo Largo del Sur, Jardines del Rey -Coco y Guillermo- y cayo Santa María -al norte de Villa Clara).

- 2008: no se desarrolló recorrido de familiarización para público especializado dado que la feria no fue dedicada específicamente a ninguna región del país. La prensa realizó un periplo al balneario de Varadero una vez concluida la misma.

- 2009: ciudades patrimoniales de Cuba (La Habana, Cienfuegos, Remedios, 
Trinidad, Sancti Spíritus, Camagüey, Bayamo y Santiago de Cuba).

- 2010: región oriental de Cuba (Camagüey, Las Tunas, Holguín, Granma -fundamentalmente Bayamo- y Santiago de $\mathrm{Cuba}^{6}$ ).

Los eventos FOTOSUB y TURNAT, con una envergadura organizativa e impacto comunicacional inferiores a FITCuba (en lo fundamental por el carácter especializado de ambos), también han favorecido la realización de fam trips.

El primero de ellos, con sede en el centro internacional de buceo El Colony, localizado en la región de Punta Francés en la isla de la Juventud (segunda en cuanto a extensión dentro del archipiélago cubano), experimentó la realización de dos ediciones en el período seleccionado (2009 y 2010), luego de una década sin celebrarse. 43 periodistas asistentes a ambas pudieron constatar las potencialidades de sus fondos marinos para la práctica de la fotografía subacuática, así como las fortalezas existentes para el desarrollo de otras modalidades turísticas afines como el buceo, de modo paralelo a las labores informativas que efectuaron durante el evento.

La mayor responsabilidad al respecto la sostuvo la convocatoria de 2010 en la cual tomaron parte 26 profesionales especializados en los referidos productos turísticos, provenientes de varios mercados emisores a Cuba y 13 representantes de medios nacionales (12 de organizaciones locales y uno de la agencia PL). En la anterior edición intervinieron 4 miembros de la prensa, de los cuales 3 eran portavoces de medios extranjeros acreditados ante el CPI-MINREX y el restante, nuevamente, un periodista de la referida institución cablegráfica.

Las dinámicas de familiarización del evento FOTOSUB, además de la constatación de las bellezas de los fondos de la región por parte de aquellos periodistas capacitados y certificados para la realización de fotografía subacuática y práctica del buceo, también han incluido sendos recorridos por el territorio de la isla de la Juventud, lo cual ha encontrado su causa en el interés colateral del certamen por difundir otros atributos de este, además de los ya referidos. Es decir que acá el concepto convencional de 'recorrido' abordado hasta ahora, adquiere matices novedosos por el hecho de que el mismo aglutina tanto los viajes efectuados en tierra propiamente como las inmersiones submarinas propiciadas a la prensa, para de modo posterior promover a gran escala,

6 En las dos últimas ediciones analizadas no se incluyó a Baracoa en los recorridos efectuados, fundamentalmente, por las condiciones no idóneas del producto dados los eventos meteorológicos que azotaron la región oriental en el período. 
gracias al carácter de masas de los medios de comunicación, la totalidad de atributos de la mencionada isla para el desarrollo del turismo internacional.

En el caso de TURNAT, las ediciones que han tenido lugar en el período seleccionado (2007 y 2009) acontecieron en la oriental ciudad de Baracoa y en la península de Zapata, localizada al sur de la provincia de Matanzas, respectivamente. Al igual que en FOTOSUB, en los recorridos de familiarización efectuados una vez concluidos sus calendarios formales, sólo tomaron parte miembros de la prensa asistente (52 en total: 24 en 2007 y 28 en 2009), en especial medios extranjeros centrados en temáticas del producto turismo de naturaleza:

- 2007: región de Baracoa. Participaron 19 periodistas extranjeros, uno de PL y 4 de medios locales.

- 2009: Hanabanilla, Villa Clara. Concurrieron 27 periodistas de medios extranjeros y uno de PL.

Estos últimos también pudieron apreciar las fortalezas de la mencionada península, a partir de su incursión en la práctica del senderismo prevista en ambas ediciones.

De conjunto, las ediciones de FITCuba, TURNAT y FOTOSUB analizadas permitieron la participación en fam trips de 1095 individuos (301 representantes de públicos prescriptores o de carácter especializado y 794 periodistas y profesionales afines), siendo el primero de estos tres cónclaves el que mayores aportes ha realizado en este sentido y la prensa el público con presencia sustantiva (gráfico $\mathrm{N}^{\circ} 1$ ): 


\section{Gráfico $\mathbf{N}^{\circ} 1$}

Participantes en recorridos de familiarización celebrados como parte de los programas de los tres principales eventos turísticos de Cuba

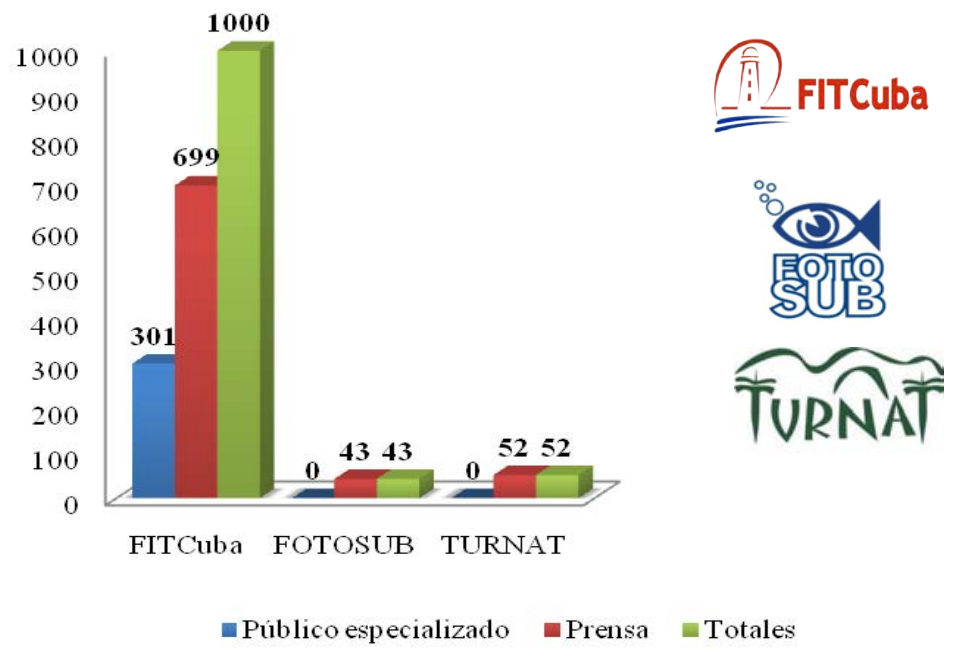

Fuente: imágenes y cifras oficiales del MINTUR

Elaboración: propia

Como bien se adelantó, otro importante escenario para la celebración de recorridos por el destino ha sido propiciado por la realización de eventos de organizaciones turísticas internacionales cuya sede fue captada por el MINTUR y/o sus catorce oficinas de Información y Promoción Turísticas en el exterior ${ }^{7}$ y las agencias del TTOO Havanatur, S.A. Los más trascendentales en el período fueron:

- XVIII congreso de la Agencia Francesa de Negocios, Turismo y Viajes AFAT Voyages (noviembre de 2007, hotel Playa Pesquero, litoral norte de Holguín). Participaron 568 congresistas, entre los cuales se encontraban 12 periodistas, fundamentalmente de medios de prensa especializados en la temática turística.

- Congreso anual del grupo canadiense ATRIUM (que aglutina a las agencias Vasco: Gama Travel, Vasco Travel y Vasco in Zellers) (septiembre-octubre de

7 Localizadas en: Canadá (2), México (1), Venezuela (1), Argentina (1), Reino Unido (1), España (1), Italia (1), Francia (1), Alemania (1), Suecia (1), Holanda (1), Rusia (1) y China (1) respectivamente. 
2009, hoteles Meliá Habana y Meliá Varadero, Matanzas). Tomaron parte 99 participantes (95 dueños de agencias de viaje, en su mayoría, y 4 periodistas de diversos medios del mercado, de carácter especializado todos).

- XXI congreso de la Asociación Empresarial de Agencias de Viajes Españolas AEDAVE (octubre-noviembre de 2010, hotel Meliá Santiago de Cuba de la oriental ciudad homónima). Asistieron 142 sujetos entre miembros de dicha organización, invitados y acompañantes y 7 periodistas de medios especializados, para un total de 149 participantes.

Estos eventos incluyeron en sus programas visitas de familiarización por las locaciones anfitrionas; los participantes en el primero y el último también recorrieron urbes localizadas en el oriente cubano (ciudades de Holguín y Bayamo, por ejemplo). En el congreso de AEDAVE, otros 2 periodistas de un medio especializado acreditado ante el CPI-MINREX, asistieron igualmente a las actividades del cónclave y al recorrido de familiarización previsto.

Otro evento de gran trascendencia que tuvo lugar en el país durante el período de análisis, pero esta vez en función de acuerdos de comunicación conjunta pactados entre el MINTUR y el TTOO alemán TUI (el mayor de toda Europa), fue el TUI Inside 2010, su más importante cónclave anual de estímulo y formación ${ }^{8}$. Participaron en este 900 personas (fundamentalmente miembros de su red de ventas y 7 periodistas), los cuales prestaron atención, gracias al recorrido desarrollado y a programas de entrenamiento, a potencialidades de regiones como La Habana, Varadero y Cayos de Villa Clara, a la vez que examinaron las condiciones de hoteles que maneja en Cuba la Corporación Española Sol-Meliá9.

Ya con anterioridad TUI había desarrollado en el país otros importantes recorridos de familiarización (conocidos en este caso como megafams a partir del gran número de participantes convocados); varios de ellos también a partir de acuerdos de comunicación conjunta.

El primero de ellos se realizó en noviembre de 2006 bajo el apelativo de Kuba Erleben Tour (La experiencia de conocer Cuba); a través de este 120 profesionales de la 8 Cuba había acogido otra sede del TUI Inside en el año 2002.

9 Presente en el país desde 1990, esta cadena administra hasta la actualidad un total de 25 hoteles de cuatro y cinco estrellas bajo cuatro de sus marcas (Paradisus, Meliá, Tryp y Sol). Dichas instalaciones se encuentran presentes en importantes regiones turísticas como La Habana, Varadero, Santiago de Cuba y Cayos. 
Gest. tur, N 16, Julio-diciembre. 2011, pp 09 - 47.

red de ventas de dicho TTOO realizaron un programa de familiarización y certificación del producto de la referida cadena ibérica, a la cual aportan la mayoría de los ingresos y estancias del mercado alemán para los hoteles que gestiona en la isla. Un año después visitó el país igual cifra de periodistas para realizar otro recorrido de familiarización, también auspiciado por TUI.

Atendiendo a la labor de este TTOO respecto al desarrollo de viajes de familiarización por la isla de 2006 a 2010, tomaron parte en los mismos un total de 1140 profesionales (1013 miembros de la red comercial y 127 periodistas).

En general, los recorridos de familiarización analizados tienen alguna incidencia en los volúmenes de emisión al destino generados de modo posterior a su conclusión. Sin embargo, los que se efectúan como parte del programa de cónclaves realizados gracias a su captación o por acuerdos de comunicación conjunta, tienen una responsabilidad superior al respecto pues en los mismos participan directivos y miembros de la red de ventas de los organizadores, es decir, actores que ofrecen información a reales y potenciales clientes y los inducen por una u otra oferta; los promotores de ventas se decantarán por determinado producto en dependencia del nivel de conocimiento que tengan sobre el mismo o en función de indicaciones emitidas.

Muy en esta línea, Katrin May, responsable del TUI Inside 2010 por la parte extranjera, declaraba: «...los trabajadores de agencias de viajes participantes aumentarán seguramente las ventas de viajes a Cuba...» (Katrin May, Inside 2010 ${ }^{10}$ )

De conjunto, los tres últimos eventos analizados y las acciones desarrolladas por TUI favorecieron la participación en recorridos de familiarización de 1806 profesionales pertenecientes a públicos especializados (fundamentalmente prescriptores) y 152 periodistas, provenientes en su gran mayoría de los mercados de origen de las referidas organizaciones turísticas foráneas, para una cifra total de 1958 individuos (gráfico $\mathrm{N}^{\circ}$ 2):

10 http://www.cubaheadlines.com/es/2010/05/25/21780/cuba_recibe_a_900_agentes_de_viajes_alemanes para_mejorar_promocion.html\#ixzz1I8dSiGfB 


\section{Gráfico $\mathrm{N}^{\circ} 2$}

Participantes en recorridos de familiarización celebrados como parte de los programas del XVIII congreso de AFAT Voyages, congreso anual de ATRIUM, XXI congreso de AEDAVE y de acciones de carácter promocional pactadas entre el MINTUR y TUI

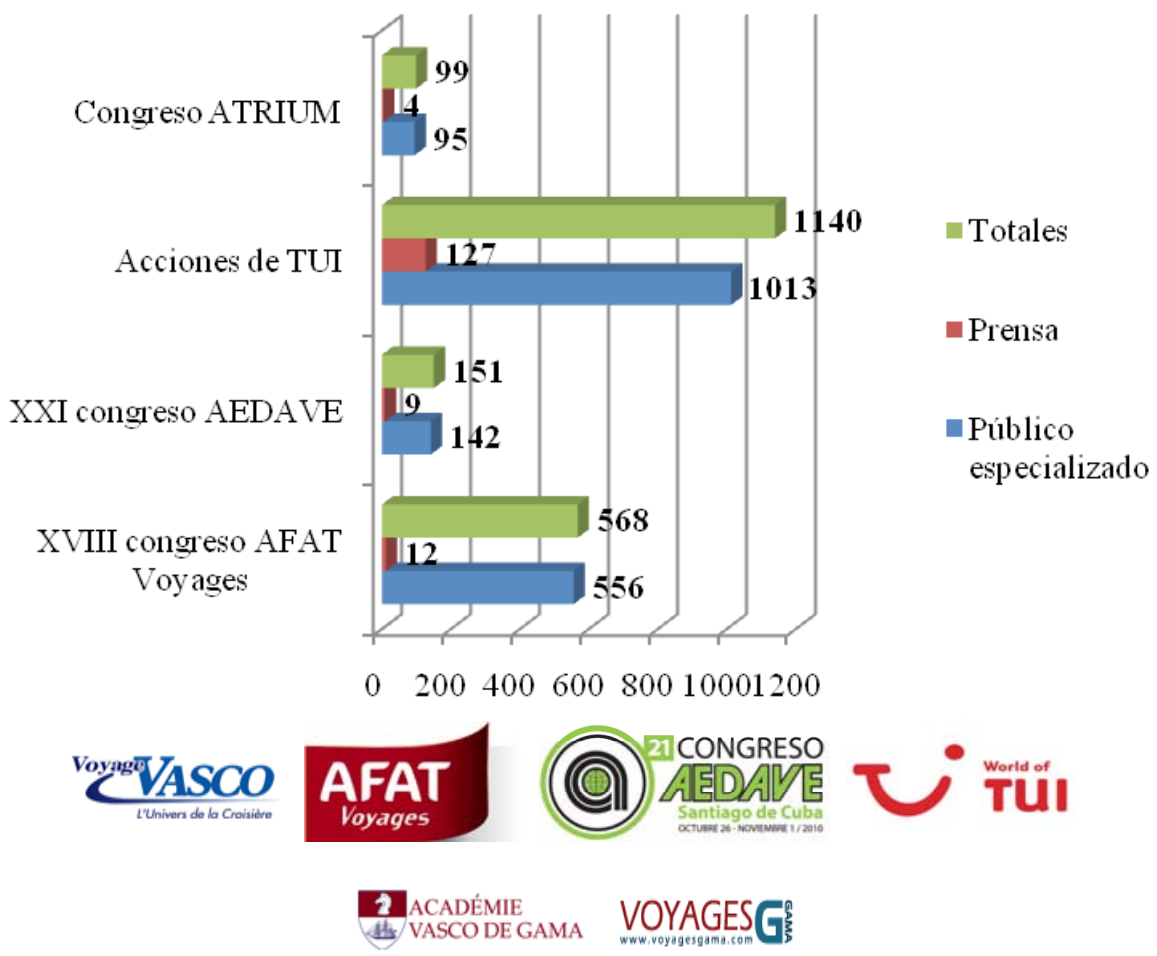

Fuentes: cifras oficiales del MINTUR y del grupo Havanatur, S.A.; imágenes: identificador visual congreso de AEDAVE (MINTUR) y otros identificadores visuales (internet)

Elaboración: propia

Como parte de este análisis también revisten notable importancia aquellos recorridos de familiarización que, de modo sistemático, han sido concebidos año tras año por el MINTUR y sus oficinas en el exterior y/o con el auspicio de las agencias de Havanatur y de otras entidades del sistema de turismo y las corporaciones internacionales asociadas a sus instituciones hoteleras. Los mismos poseen, como norma, una envergadura menor 
que los anteriormente analizados y no se producen en estos mezclas de públicos ${ }^{11}$.

A modo de conclusiones parciales, puede afirmarse que, en consideración de la totalidad de eventos y acciones abordados, de 2006 y hasta 2010 han recorrido el destino Cuba o una selección deliberada de sus regiones o instituciones (administradas o no por el sector), la cantidad de 3053 sujetos, con preponderancia para el público especializado o mediador entre el mismo y sus visitantes finales (69 \%) (Gráfico $\left.N^{\circ} 3\right)$ :

\section{Gráfico $\mathbf{N}^{\circ} 3$}

Tipos de públicos participantes en recorridos de familiarización analizados en el período 2006-2010

- Público especializado $\quad$ Prensa

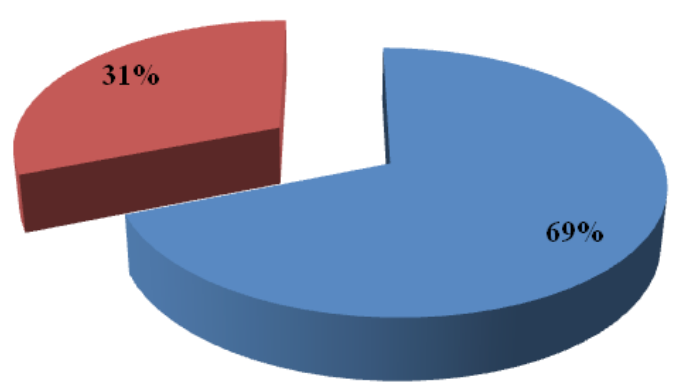

Fuente: cifras oficiales del MINTUR y del grupo Havanatur, S.A.

Elaboración: propia

También puede presumirse que las mayores cifras de participantes en recorridos de familiarización por el destino que han sido objeto de análisis, las han aportado los eventos internacionales captados por el MINTUR y/o entidades del sistema de turismo así como otras acciones de carácter promocional efectuadas en Cuba por parte de socios extranjeros del rubro turístico (64\%) (gráfico $\mathrm{N}^{\circ} 4$ ). En el caso de los eventos organizados directamente por el MINTUR, los periplos de familiarización efectuados como parte de sus programas que mayor número de integrantes han convocado, son los de FITCuba (33 $\%$ de los 3053 referidos) (gráfico $\mathrm{N}^{\circ}$ 5):

11 En próximas ampliaciones de este estudio, actualmente en desarrollo, también se tomarán en cuenta estadísticas arrojadas por dichas acciones. 


\section{Gráfico $N^{\circ} 4$}

Participantes en recorridos de familiarización por el destino Cuba como parte del programa de los eventos organizados por el MINTUR y de otras acciones promocionales analizadas

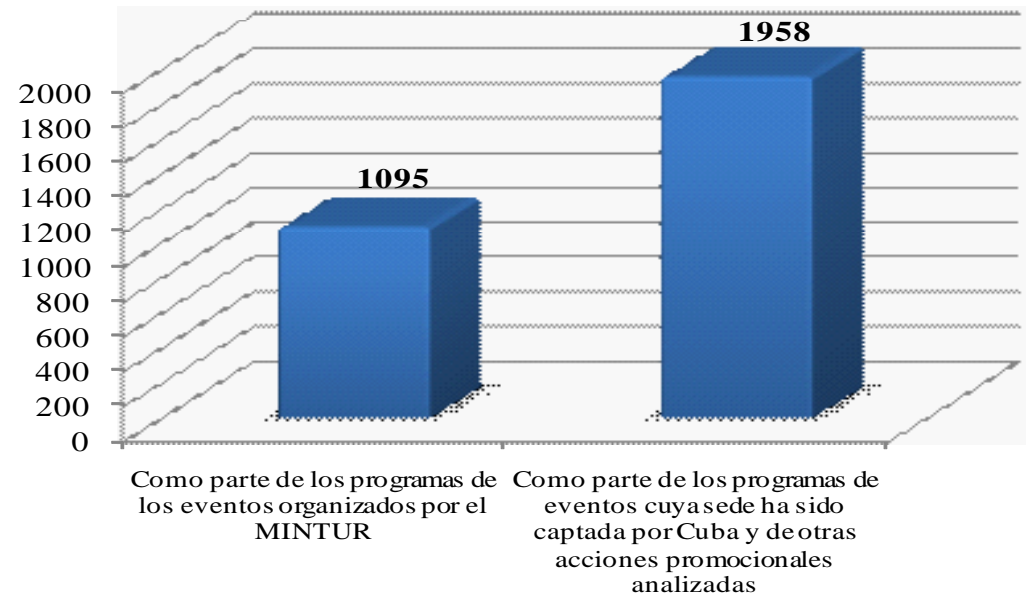

Fuente: cifras oficiales del MINTUR y del grupo Havanatur, S.A.

Elaboración: propia

\section{Gráfico $N^{\circ} 5$}

Participantes en recorridos de familiarización por el destino Cuba como parte del programa de las ediciones de FITCuba analizadas y del resto de las acciones promocionales abordadas

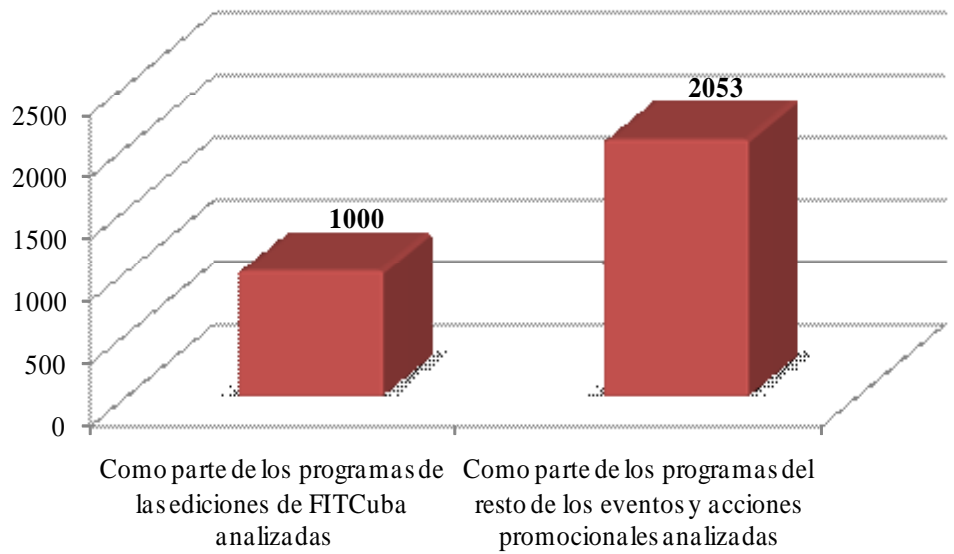

Fuente: cifras oficiales del MINTUR y del grupo Havanatur, S.A.

Elaboración: propia 
Gest. tur, N 16, Julio-diciembre. 2011, pp 09 - 47.

En cuanto a la presencia de periodistas, fotógrafos y otros especialistas cercanos en estos recorridos de familiarización (946 profesionales en total), los números sobresalientes se reservan para los provenientes de los más importantes mercados emisores (96 \%), como puede apreciarse en el cuadro $\mathrm{N}^{\circ}$ 2, entre los cuales puede hallarse tanto prensa especializada en temáticas turísticas y de ocio como la que se concentra en la transmisión de información al gran público. De igual modo, se decanta de la misma que FITCuba es el espacio propiciador de la mayor afluencia de este público para participar en las referidas acciones promocionales (74 \%):

\section{Cuadro $\mathrm{N}^{\circ} 2$}

Tipología de prensa participante en recorridos de familiarización efectuados como parte de los programas de la totalidad de eventos y acciones promocionales analizada (2006-

2010)

\begin{tabular}{|c|c|c|c|c|}
\hline \multirow[b]{2}{*}{$\begin{array}{c}\text { Eventos y otras acciones } \\
\text { promocionales cuyos } \\
\text { programas han incluido } \\
\text { fam trips }\end{array}$} & \multicolumn{3}{|c|}{ TIPOLOGÍA DE PRENSA PARTICIPANTE } & \multirow[b]{2}{*}{ TOTAL } \\
\hline & $\begin{array}{c}\text { Invitada desde } \\
\text { mercados emisores al } \\
\text { destino Cuba } \\
\end{array}$ & $\begin{array}{l}\text { Acreditada ante el } \\
\text { CPI-MINREX }\end{array}$ & $\begin{array}{c}\text { Cubana, en lo } \\
\text { fundamental } \\
\text { de alcance } \\
\text { nacional } \\
\end{array}$ & \\
\hline FITCuba & 687 & 6 & 6 & 699 \\
\hline 2006 & 57 & 0 & 0 & 57 \\
\hline 2007 & 120 & 0 & 0 & 120 \\
\hline 2008 & 170 & 0 & 0 & 170 \\
\hline 2009 & 184 & 3 & 0 & 187 \\
\hline 2010 & 156 & 3 & 6 & 165 \\
\hline FOTOSUB & 26 & 3 & 14 & 43 \\
\hline 2009 & 0 & 3 & 1 & 4 \\
\hline 2010 & 26 & 0 & 13 & 39 \\
\hline TURNAT & 46 & 0 & 6 & 52 \\
\hline 2007 & 19 & 0 & 5 & 24 \\
\hline 2009 & 27 & 0 & 1 & 28 \\
\hline XXVIII congreso AFAT & 12 & 0 & 0 & 12 \\
\hline Congreso anual ATRIUM & 4 & 0 & 0 & 4 \\
\hline XXI congreso AEDAVE & 7 & 2 & 0 & 9 \\
\hline $\begin{array}{l}\text { Evento TUI Inside } \\
2010 \text { y otras acciones } \\
\text { efectuadas por este } \\
\text { TTOO }\end{array}$ & 127 & 0 & 0 & 127 \\
\hline TOTALES & 909 & 11 & 26 & 946 \\
\hline
\end{tabular}

Fuente: cifras oficiales del MINTUR y del grupo Havanatur, S.A.

Elaboración: propia 
Las regiones más frecuentemente visitadas como parte de los recorridos abordados, han sido, en este orden:

- La Habana: de conjunto con Varadero, es uno de los polos turísticos más importantes de todo el destino. Ha sido sede de las cinco ediciones de FITCuba analizadas, de una parte de las sesiones formales del congreso de ATRIUM y parte permanente de los programas de familiarización impulsados por TUI.

- Varadero: región incluida en los recorridos de familiarización correspondientes a 2006, 2008 y 2009 de FITCuba. La segunda parte de los debates del congreso de ATRIUM se efectuó en la misma, mientras que TUI también ha previsto al balneario como parte de los fam trips ya analizados.

- $\quad$ Región oriental: FITCuba 2010 se centró en la promoción de la misma mientras que en la edición de 2009, dedicada a las ciudades patrimoniales del destino, Camagüey, Bayamo y Santiago de Cuba se incluyeron en su correspondiente periplo de familiarización. Además, de importantísima envergadura fueron los recorridos efectuados por la región como parte del XVIII congreso de AFAT Voyages y del XXI de AEDAVE. A todo lo anterior, añádase que la sede del evento TURNAT 2007 fue Baracoa, en Guantánamo.

- Z Zona central: FITCuba 2006 se dedicó a dicho producto; la edición de 2007 previó estancias como parte de los desplazamientos de familiarización en cayo Santa María y Jardines del Rey y en otras locaciones de las provincias de Villa Clara y Sancti Spíritus; y la correspondiente a 2009 propició la visita a las ciudades de Cienfuegos, Santa Clara, Remedios, Trinidad y Sancti Spíritus, ciudad última a la que retornó prensa asistente a FITCuba 2010. Finalmente, varios periodistas realizaron una visita a la región de Hanabanilla como parte de las actividades post-evento del TURNAT 2009.

- Cayos de Cuba: el cénit en cuanto a su promoción tuvo lugar durante FITCuba 2007 cuando el evento se dedicó a los mismos. Gran contribución en cuanto a su conocimiento también ha desarrollado TUI al incluirlos en varios de los periplos promocionales examinados (fundamentalmente aquellos donde Sol-Meliá tiene presencia: cayo Largo del Sur, cayos de Villa Clara y Jardines del Rey).

- Archipiélago de los Canarreos: en especial por la celebración en la isla de la Juventud de las dos ediciones analizadas del evento FOTOSUB.

En el gráfico $\mathrm{N}^{\circ} 6$ se puede apreciar la localización geográfica dentro del 
territorio cubano de estas regiones y, especialmente en la oriental y la central, de varias ciudades y otros productos que han sido objeto de recorridos de familiarización durante el período de interés:

\section{Gráfico $\mathbf{N}^{0} 6$}

Regiones y productos del destino Cuba que mayor atención han generado durante importantes recorridos de familiarización desarrollados entre 2006 y 2010

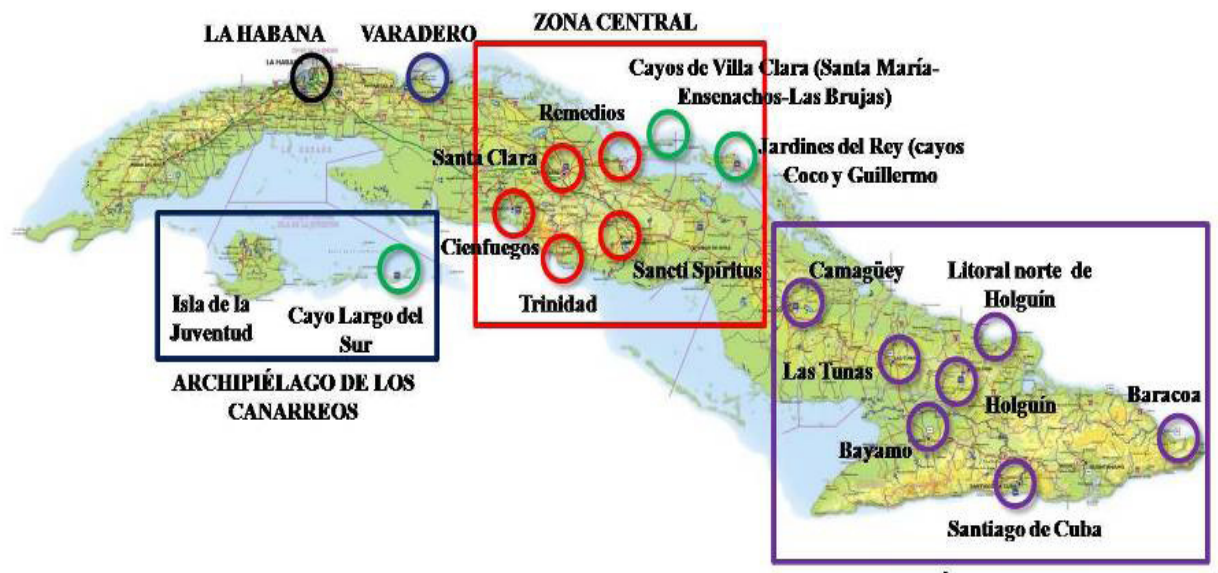

REGIÓN ORIENTAL

Fuente: análisis propio a partir de datos del MINTUR y del grupo Havanatur, S.A.

Elaboración: propia

Los países de procedencia de los participantes en estos recorridos han sido, en lo fundamental, Canadá y miembros de la Unión Europea (UE), sobre todo Reino Unido, Alemania, España, Francia e Italia, sin desestimar la importante pujanza que han adquirido en los últimos años otras regiones como Rusia, Europa del este y Latinoamérica (sobre todo México y Argentina). Todo lo anterior encuentra explicación en las estrategias de comercialización establecidas para el destino, a partir de las cuales dichas regiones han aportado históricamente los mayores volúmenes anuales de visitantes a Cuba.

De modo general, los fines establecidos para este tipo de acciones han sido cumplimentados. Las posibilidades de informar y persuadir que han abierto los recorridos de familiarización analizados, han contribuido posteriormente a la generación de decisiones de un saldo positivo para el destino Cuba por parte de socios extranjeros 
participantes, como regla general. Asimismo, como acción de RRPP por excelencia, estos viajes han constituido una oportunidad de lujo para hacer saber a audiencias estratégicas para el desarrollo del turismo, mensajes de marcada trascendencia para el mismo, sobre todo cuando se ha previsto la invitación a la prensa para tomar parte en aquellos.

No obstante, todavía persisten elementos a considerar que restan mayor efectividad a los recorridos de familiarización que organiza el MINTUR y varias de sus entidades, si bien en este frente se ha avanzado ostensiblemente en relación a etapas anteriores de trabajo, en lo fundamental, por la paulatina incorporación de egresados de la licenciatura en Comunicación Social ${ }^{12}$ a dispositivos de comunicación y RRPP del sistema de turismo (sobre todo de su aparato central), así como por el entendimiento creciente por parte de directivos y otros decisores de la subjetividad del fenómeno de la comunicación y de la real imposibilidad de juzgarlo desde similares posturas a las aplicadas al Marketing, ventas, comercialización u otras actividades cercanas.

Uno de ellos es el estimar en tanto participantes, como generalidad, a representantes de organizaciones provenientes de los más importantes mercados emisores, lo cual cercena una gran posibilidad para individuos o grupos estratégicos localizados en regiones emergentes (Asia, Oceanía, África y Medio Oriente, por ejemplo), ávidos también de constatar las fortalezas y perspectivas del producto turístico cubano; y lo mismo ocurre con la prensa, limitándose así las probabilidades de elevar el conocimiento sobre el destino en países del mundo donde poco o casi nada se sabe, no sólo sobre turismo, sino de Cuba en general.

Por último, aunque quedan claros las metas y fines globales para los que se desarrollan estas acciones, todavía deben perfilarse mejor cuestiones como la formulación de objetivos de comunicación más precisos, en función de su certera medición posterior. En este sentido, resulta bien frecuente aún la exaltación de los resultados de viajes de

12 Esta carrera universitaria se instauró en Cuba formalmente en el año 1991, desde la óptica de un perfil amplio donde se combinaba el aprendizaje de técnicas y lenguajes de los medios masivos y de otras disciplinas del campo de la Comunicación Social como la Comunicación Institucional, RRPP, Publicidad, Propaganda..., pero con preponderancia para lo relativo al Periodismo. En el año 2000 se implementa un nuevo plan de estudios para la licenciatura en Comunicación Social y otro propiamente para la carrera de Periodismo (tanto en la universidad de La Habana como en la de Oriente), donde la segunda continuaba responsabilizada con la formación de los profesionales de la prensa y la primera centraba su atención en ámbitos de creciente relevancia en el contexto nacional e internacional como la comunicación en organizaciones. En 2008 se inicia la aplicación de nuevos programas de estudio y, desde entonces, la licenciatura en Comunicación Social prevé, además del ámbito organizacional o institucional, otros como el mediático y los espacios de desarrollo local (Comunicación para el Desarrollo). 
familiarización, en especial los constituidos por prensa, a partir de los costos inferiores en los que incurrió la acción, tomando para ello como patrón las tarifas vigentes para inserción de material publicitario de la campaña de destino en vigor u otro de interés para el MINTUR y las entidades del sistema de turismo, en idénticos o similares medios masivos u otros soportes comunicativos.

En las figuras $\mathrm{N}^{\mathrm{o}}$ 1, 2, 3 y 4 se han colocado imágenes de algunos recorridos de familiarización que fueron objeto de análisis del presente trabajo:

\section{Figura $\mathbf{N}^{0} 1$}

Prensa asistente a TURNAT 2007 desarrolla recorrido por Baracoa que le permite

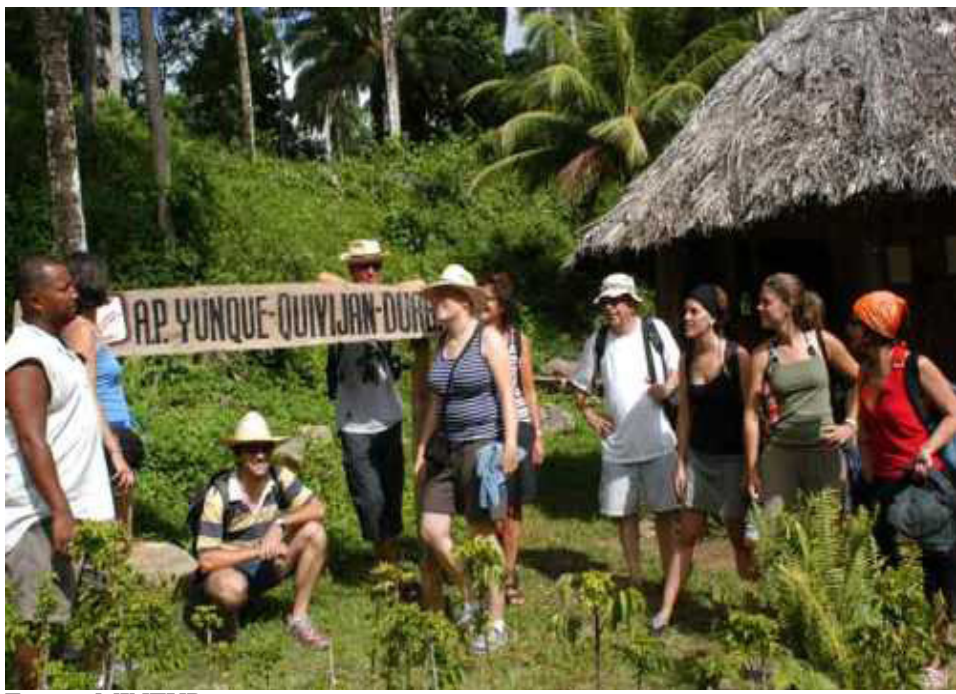

Fuente: MINTUR 


\section{Figura $\mathbf{N}^{\circ} 2$}

Prensa extranjera invitada a FITCuba 2009 aprecia las facilidades del hotel Villa La Granjita, en Villa Clara

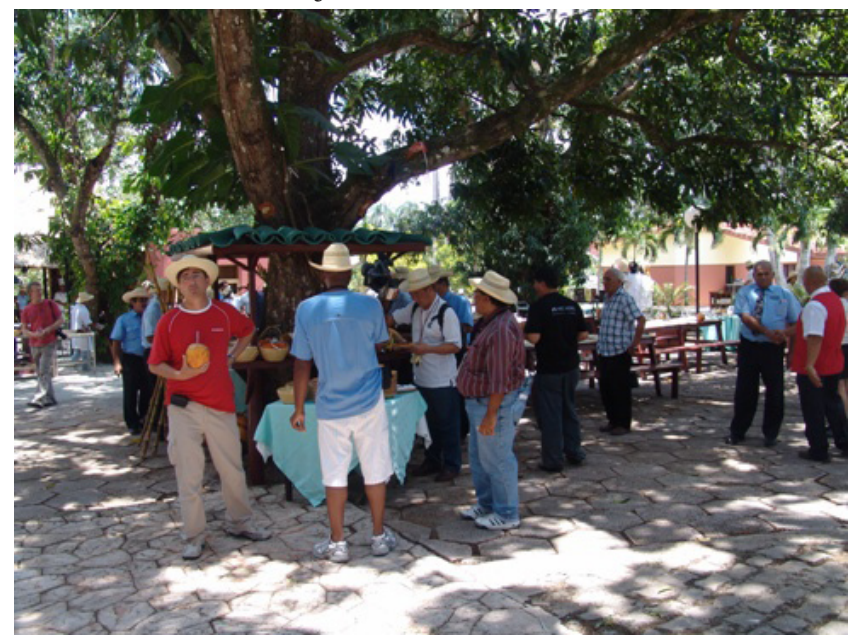

Fuente: MINTUR

\section{PROPUESTA}

Intentando alejar de este trabajo cualquier afán recetario o instrumental y tomando en consideración la experiencia del autor en materia de organización de recorridos de familiarización, sin desestimar los aspectos teóricos y empíricos sostenidos durante el mismo, se proponen diez elementos a considerar por parte de organismos y organizaciones turísticas a la hora de concebir y desarrollar acciones de esta tipología:

- Tener la suficiente claridad para apreciar que los recorridos de familiarización constituyen, en esencia, una táctica de las RRPP con independencia de sus marcados acentos promocionales.

- Planear el desarrollo de recorridos de familiarización con el suficiente tiempo a fin de que le sean asignadas las necesarias cantidades de presupuesto, y que pueda lograrse la precisa interrelación y equilibrio con el resto de las tácticas previstas dentro de un programa de acción y comunicación para cierto período de trabajo.

- Tomar muy de cerca los planes de Marketing, comercialización, desarrollo de productos y ventas para realizar recorridos de familiarización lo más certeros 
posibles, según las estrategias por áreas de resultados y globales trazadas por organizaciones y destinos turísticos.

- Imbuir en su concepción y diseño, mucho antes de la realización del viaje, a cuanto personal de terceras áreas dentro de organismos y organizaciones turísticas competa, así como a agentes provenientes de otros sectores del desarrollo local y nacional -si es que se previeran instituciones o productos dentro del periplo no gestionados precisamente por los primeros.

- Conceptualizar de modo profundo y dialéctico el programa del viaje de familiarización, en función de sus objetivos, cantidad de individuos previstos, el tiempo con el que se cuenta así como de los recursos disponibles para sustentar económica y materialmente la acción.

- Intentar prever, con suficiente antelación, la totalidad de las cuestiones logísticas necesarias para el buen desenvolvimiento de la acción, por muy fútiles que puedan vislumbrarse algunas (transporte, alojamiento, alimentación, guías de turismo...).

- Seleccionar de modo cuidadoso los participantes en recorridos, según los objetivos trazados para los mismos tanto en el corto como en el mediano y largo plazos.

- Asignar personal de las áreas de RRPP y comunicación de organismos y/u organizaciones turísticas (de modo preferencial aquellos que moderaron el proceso de conceptualización del recorrido), lo suficientemente capacitados en la materia así como conocedores del o los productos a mostrar, que funjan en calidad de tour leaders o mediadores entre los participantes en el mismo y los anfitriones de cada una de las regiones/instituciones a visitar.

- Evaluar la acción de modo integral y especialmente en términos de comunicación, en función de mostrar a decisores y otros públicos de interés, los resultados obtenidos en materia de conocimiento y reconocimiento del destino/organización/ producto turístico por parte de los asistentes y de otras audiencias, y no sólo en relación con metas comerciales fomentadas o impulsadas.

- Mantener y aquilatar los vínculos establecidos con los participantes en recorridos de familiarización una vez concluidos estos, sobre todo con aquellos que hayan arrojado los saldos más positivos para los promotores. 


\section{CONCLUSIONES}

- Los recorridos de familiarización constituyen en destinos turísticos una importante herramienta de las RRPP abocadas a la consecución de metas de Marketing, atendiendo a la contribución directa e indirecta que realizan dentro de los esfuerzos globales de comercialización y promoción de organizaciones y productos del rubro.

- Una de las cuestiones más trascendentales como parte de su concepción y desarrollo es la definición de objetivos a alcanzar en términos comunicacionales (y de manera colateral, el modo en que la acción contribuye a metas de Mercadotecnia y globales de las partes promotoras), así como de los posibles públicos a invitar para participar en los recorridos.

- La dimensión pública que alcanzan los destinos y productos visitados por profesionales de los medios de comunicación, en aquellos trabajos que son llevados a soportes mediáticos, hacen de este tipo de periplos una táctica sumamente delicada en todos los órdenes, que precisa de una milimétrica coordinación y un coherente desenvolvimiento. Por ello los viajes de prensa meritan un pensamiento especial dentro de las dinámicas promocionales que profesionales de las RRPP desarrollan en escenarios turísticos, a fin de lograr mayores niveles de conocimiento, reconocimiento y notoriedad de productos de su interés, en consideración de la apelación de esquemas de los mass media.

- $\quad$ En el destino Cuba, desde 2006 y hasta 2010:

- Los viajes de familiarización desempeñaron un importante papel en la labor de comunicación promocional desplegada por el MINTUR como parte de sus planes y campañas de RRPP, de conjunto con otras prácticas comunicacionales.

- Algunos de los más relevantes viajes de familiarización efectuados, tuvieron lugar en tanto componente de los programas de eventos de gran trascendencia para el destino, organizados directamente por el MINTUR: Feria Internacional de Turismo (FITCuba), Evento Internacional de Fotografía Subacuática (FOTOSUB) y Evento Internacional de Turismo de Naturaleza (TURNAT), sin desdeñar otros que acontecieron como parte de las actividades previstas para encuentros efectuados en el país, en calidad de sedes de eventos captadas internacionalmente, entre los cuales destacan el XVIII congreso de AFAT Voyages (2007), congreso anual del grupo ATRIUM (2009) y el XXI congreso de AEDAVE (2010). 
- A tenor de los contratos de comunicación cooperada establecidos entre el MINTUR e importantes socios de la operación turística en el mundo, otros eventos desarrollaron sus cronogramas de trabajo en el país; como parte de los mismos también se previeron diversos recorridos de familiarización. Destaca al respecto TUI, que desarrolló el evento TUI Inside 2010 y promovió la realización de terceras acciones de familiarización con el destino.

- FITCuba es, entre todos los eventos ponderados que organiza directamente el MINTUR, el espacio que mayores índices de participantes ha arrojado para los recorridos de familiarización efectuados como parte de los programas de los mismos. En el capítulo correspondiente a las acciones de este tipo impulsadas dentro del destino por organizaciones internacionales, TUI centra la mayor atención entre todas.

- En consonancia con el carácter promocional que ha prevalecido en los viajes analizados, los públicos con más participación han sido el especializado (Tour Operadores, Agencias de Viajes, Líneas Aéreas, representantes de cadenas hoteleras, entre otros) y periodistas. Y aunque el mayor protagonismo en cuanto a estadísticas lo ha tenido el primero, ha sido la prensa -sobre todo la proveniente de importantes mercados emisores a Cuba-, un foro al cual se ha prestado especial atención por parte de los promotores de estos recorridos y de otros agentes decisores sobre el rubro, lo cual igualmente corrobora las tesis sostenidas al respecto en la sección teórica del presente trabajo.

- Las regiones más visitadas como parte de estos recorridos de familiarización han sido La Habana, Varadero y las zonas central y oriental de Cuba, si bien otras que de modo creciente han venido aumentando su potencial turístico en los últimos años, han tenido una paulatina mayor acogida dentro de los mismos. Descuellan al respecto la red de cayos y las ciudades con altos valores patrimoniales y arquitectónicos.

- Respecto a los países de origen de los participantes en dichos fam trips, los espacios honoríficos corresponden a los más notables mercados emisores a Cuba, sobre todo Canadá y miembros de la Unión Europea.

- Aún persisten determinadas debilidades respecto a los recorridos de familiarización que se realizan por el destino. En este sentido, debe seguírsele prestando mayor atención a cuestiones como la definición precisa de objetivos de comunicación y, en función de estos, de los participantes; ello permitirá, para venideras etapas de trabajo, una valoración más certera en términos de 
conocimiento y reconocimiento de instituciones o productos constatados, y no sólo en función de los aportes realizados a metas comerciales del rubro, lo cual también es menester considerar pero más bien desde un plano colateral.

- Ante la constatada carencia de modelos teóricos (sobre todo en el espacio de reflexión latinoamericano) que sistematicen la esencia y dinámicas de los recorridos de familiarización, como una de las más importantes tácticas de RPPP a desplegar en destinos turísticos, se hace preciso formular nuevas propuestas y esquemas de aplicación -desde experiencias particulares- para dotar, tanto a la táctica en sí como a la disciplina en general, de una mayor cientificidad y rigor profesional. Ello, sin dudas, contribuye a un superior reconocimiento social de la última así como al más pleno afianzamiento de sus presupuestos en cualquier espacio de actuación.

\section{RECOMENDACIONES}

Algunas recomendaciones a tomar en cuenta por estudiosos y profesionales de la comunicación y las RRPP que se desenvuelven en sistemas turísticos, sobre todo cubanos, en función de la optimización de recursos y esfuerzos demandados por la organización de recorridos de familiarización, pudieran ser las siguientes:

1. Continuar sistematizando desde la teoría, conocimiento y práctica acumulados respecto a la organización de recorridos de familiarización, en función del perfeccionamiento continuo de esta táctica de las RRPP en el contexto del sistema de turismo de Cuba.

2. Realizar indagaciones similares a la presente, tomando como patrón de análisis regiones que ofrecen competencia directa al destino en materia turística (sobre todo del Caribe y Centroamérica), a fin de valorar las analogías y contradicciones que se establecen en este sentido por ambas partes.

3. Seguir profundizando en lo concerniente a la organización de recorridos de familiarización en el destino Cuba, tanto en otros períodos como considerando también lo gestado al respecto por la totalidad de entidades del sistema turístico y las oficinas de Promoción e Información Turísticas del MINTUR radicadas en el exterior.

4. Valorar para próximas etapas de trabajo la realización de recorridos de familiarización integrados por audiencias no abordadas en este estudio 
(trabajadores del sistema turístico, representantes de organismos y organizaciones con incidencia directa e indirecta sobre el desarrollo del rubro, grupos de presión...), dirigidos igualmente a mostrar las potencialidades del destino Cuba, pero con fines menos comerciales y con la atención centrada en cuestiones como la formación, capacitación y sensibilización de alguno(s) de estos públicos en materia turística, así como en la minimización de posibles conflictos existentes entre el sector y los mismos, entre otros elementos a considerar.

5. Quelospromotores derecorridos defamiliarizacióndel MINTURy delasentidades del sistema de turismo, establezcan un grado superior de conceptualización para estos, prestando mayor cuidado a aspectos estratégicos como la definición de objetivos de comunicación, selección de públicos participantes y evaluación de resultados obtenidos en el ámbito comunicacional así como en lo relativo al aporte a metas comerciales. La consideración de la propuesta (o parte de la misma) que se realiza en esta investigación, puede propender en alguna medida a dicho propósito.

\section{AGRADECIMIENTOS}

Para la realización de este trabajo fueron muy valiosos los aportes, experiencia y colaboración de los especialistas Ms. C. Yoanki J. Nieves Rodríguez, Lic. Alberto S. Encinoso Lemus y Lic. Gillian Ezquerra Quintana, funcionarios de la dirección de Comunicación del MINTUR; de la especialista Lic. Isabel Docampo Torres, funcionaria de la dirección Comercial de dicho organismo; así como del Lic. Jorge Félix Salazar, presidente de las agencias canadienses Hola Sun Holidays y Caribe Sol, del grupo Havanatur, S.A. y de la Lic. Marisabel González Hernández, directora de la oficina de Información y Promoción Turísticas del MINTUR radicada en Alemania. 


\section{REFERENCIAS BIBLIOGRÁFICAS}

Acerenza, Miguel A (1985). Promoción turística. Un enfoque metodológico. 3a. ed. México, D.F.: Trillas,.

Cordero Durán, Lisandra y González Hernández, Yadir.( 2008) “Aproximación a las representaciones sociales del Comunicador Social en actores sociales relevantes para su desarrollo, en tanto figura profesional, en Cuba". Tesis de grado en Comunicación Social. Universidad de La Habana, Facultad de Comunicación, La Habana, Cuba.

Headlines Digital Edition, [en línea] fecha de consulta: 27 Marzo 2011]. Disponible en: http://www.cubaheadlines.com/es/2010/05/25/21780/cuba recibe a 900 agentes_de_viajes_alemanes_para_mejorar_promocion.html\#ixzz1I8evWof7.

García Iglesias, Dagoberto (2009) "Lo que el viento se llevó... Una mirada a la institucionalización y profesionalización de las Relaciones Públicas en el turismo cubano actual”. Tesis de grado en Comunicación Social. Universidad de La Habana, Facultad de Comunicación, La Habana, Cuba.

(2010) "Relaciones Públicas aplicadas a contextos turísticos. Aproximaciones al fenómeno desde la emergencia de un enfoque integrador”. En: Convención Internacional de Estudios Turísticos Facultad de Turismo de la Universidad de La Habana, Buró de Convenciones de Cuba, Palacio de Convenciones.

George Farray, Liz Laura Y González Lucena, Danny.(2009) “Color cubano en las CULTURALES. Un acercamiento a la mediación establecida por la cultura organizacional de los actores que producen los segmentos culturales del Sistema Informativo de la Televisión Cubana, en la representación de la cultura cubana proyectada por dichos espacios”. Tesis de grado en Periodismo. Universidad de La Habana, Facultad de Comunicación, La Habana, Cuba.

Ministerio de Turismo (2005). Resolución 57 de 2005 del Ministro de Turismo: Política de Comunicación Promocional para el Sistema de Turismo. La Habana, Cuba: MINTUR, 2005.

Muñoz Oñate, Fernando (2000). Marketing turístico. Madrid: Centro de Estudios Ramón Areces, S.A.

Piedra Rodríguez, Mario. (2002) Relaciones Públicas: definición, principales conceptos y acciones. En: Colectivo de Autores. Manual de Relaciones Públicas. La Habana: Félix Varela, 2002. pp. 41-98. 
Dennis L. Wilcox et al (2001). Relaciones Públicas. 6a. ed. Madrid: Pearson Educación, S.A., 2001.

Rivero Hernández, Magda. (2010) Bases teórico-metodológicas para la evaluación del sistema de comunicación en empresas cubanas y Organismos de la Administración Central del Estado (OACE). Tesis doctoral en Ciencias de la Comunicación). Universidad de La Habana, Facultad de Comunicación, La Habana, Cuba. (2009) Relaciones Públicas. Entre el marketing y la comunicación. Espacio, (13): 34-37.

Rojas Orduña, Octavio Isaac. (2005) Relaciones Públicas: la eficacia de la influencia. Madrid: ESIC.

Seaton, Tony y Woodward, Ian. (en línea) Evaluación de las Actividades de Marketing de las ONT, Revisión sistemática. Madrid: Organización Mundial del Turismo, [2004] [fecha de consulta: 29 Enero 2009]. Disponible en: http://www.e-unwto. org/content/p53733/fulltext.pdf.

Serra, Antoni. (2003) Marketing turístico. Madrid: ESIC.

Ponencia presentada en el sexto congreso de Ciencias Aplicadas al Turismo TURICIENCIA Cuba 2011, auspiciado por la Red de Investigaciones Aplicadas al Turismo RIATUR, la facultad de Geografía de la universidad de La Habana y el centro de Estudios Turísticos de la universidad de La Habana. Hotel Tryp Habana Libre, La Habana, del 2 al 4 de mayo de 2011.

Recibido: 18/07/2011

Aprobado: 03/10/2011

Arbitrado anónimamente 